valuables. They have now been found in the stonevaulted basement of the Museum, packed in three cases which were labelled as containing various astronomical instruments of the late eighteenth century and mixed with a number of cases actually containing such instruments. By this means, it is conjectured, Dr. Gunther had intended not only to protect them from air attack but also from the searches of a possible invader. It is hoped that the Museum will open next October, when these treasures will be displayed once more to public view.

\section{Use of Selenium for Pest Control}

INVESTIGATIONS have shown that selenium salts, among other substances applied to the soil, are taken up by plants and will make the plants so treated poisonous to certain pests that attack them. Selenium compounds, such as sodium selenate, have lately been tried by a few growers for the control of chrysanthemum eelworm and some other pests of flower crops. This is dangerous because selenium compounds are poisons to man ; moreover, they may persist for long periods in the soil, and if food crops are grown later in treated soil the plants may take up the poison in sufficient amount to make them injurious to health if eaten. For the present, neither sodium selenate nor any selenium compound should in any circumstances be used for pest control purposes. The Ministry of Agriculture and Fisheries understands that no proprietary insecticide containing selenium is manufactured in Great Britain.

\section{Astronomical Instruments}

Sir Howard Grubb, Parsons aNd Co. have issued a catalogue of some of the astronomical equip. ment designed and manufactured by the Company. The photographs and illustrations are arranged in sections as follows: reflectors, refractors, domes, driving mechanism, breechpieces, transits, coelostats, objectives and mirrors, and also "In the Workshops". The illustrations do not represent in every detail the latest design practice because advances in engineering technique during the War are now applicable in some cases to the design of astronomical equipment. At the end of the book there is a list of the large telescopes-twelve altogether-manufactured by the Company between 1927 and 1947.

\section{The Night Sky in August}

NEw moon occurs on Aug. 5d. 04h. 13m., U.T., and full moon on Aug. 19d. 17h. $32 \mathrm{~m}$. The following conjunctions with the moon take place: Aug. 2d. 07h., Venus $9^{\circ}$ S.; Aug. 9d. 05h., Mars $2^{\circ}$ S. ; Aug. 14d. 04h., Jupiter $4^{\circ}$ N. ; Aug. 31d. 03h., Venus $8^{\circ} \mathrm{S}$. Mercury, which rises an hour before the sun on Aug. 1, is in superior conjunction on Aug. 11, and is badly placed for observation during the greater portion of the month. Venus rises at $1 \mathrm{~h} .40 \mathrm{~m}$., $1 \mathrm{~h}$. $20 \mathrm{~m}$. and $1 \mathrm{~h} .15 \mathrm{~m}$. at the beginning, middle and end of the month, respectively, and can be seen for some hours before sunrise. The stellar magnitude of the planet is about $\mathbf{- 4 . 2}$ throughout August, and the visible portion of the illuminated disk varies from 0.3 to $0 \cdot 47$. Mars sets at $21 \mathrm{~h}$. $38 \mathrm{~m} ., 20 \mathrm{~h}$. $55 \mathrm{~m}$. and $20 \mathrm{~h} .10 \mathrm{~m}$. at the beginning, middle and end of the month, respectively, and can be seen for a short time after sunset. Jupiter, in the constellation of Ophiuchus, can be seen low in the evening, setting at $0 \mathrm{~h} .25 \mathrm{~m}$. and $22 \mathrm{~h} .30 \mathrm{~m}$. on Aug. 1 and 31 , respectively. The planet is stationary on Aug. 16. Saturn, in conjunction with the sun on Aug. 19, is not well placed for observation. On Aug. 31 the planet rises an hour before the sun but is practically unobservable. No occultations of stars brighter than mag. 6 occur during August. The Perseid meteors attain a maximum about Aug. 10-12, but moonlight will partly interfere with the observation of the shower at that time.

\section{Announcements}

WE regret to announce the death of Sir Clifford Paterson, O.B.E., F.R.S., director of the Research Laboratories of the General Electric Co., Ltd., which occurred on July 26.

Prof. Raoul Combes, professor of plant biology in the University of Paris, has been elected to the Section of Botany of the Paris Academy of Sciences, in succession to the late Prof. P. A. Dangeard.

IN commemoration of the centenary of the birth of Baron Roland von Eötvös (see Nature, July 24, p. 135), a small collection illustrating his work has been arranged at the Science Museum, London. It will remain on view until September.

THE Managers of the Royal Institution have appointed Dr. D. P. Riley, University demonstrator in the Department of Mineralogy and Petrology, Cambridge, to the Dewar Research Fellowship, tenable in the Davy Faraday Laboratory of the Royal Institution. Dr. Riley will undertake a programme of research on the application of methods of X-ray diffraction analysis to the study of the structure of colloidal systems and biological material.

PART of the exhibition of photographs demonstrating the value of air photography to archæology recently held in London (Nature, July 17, p. 96) has been transferred to the Ashmolean Museum, Oxford, for the period August 2-September 4.

A symposidm on the "Chemistry, Metabolism and Biological Effects of Steroid Hormones" will be held in the University of Wisconsin, during September 68 , under the auspices of the University of Wisconsin and the U.S. National Research Council Committee on Growth, acting for the American Cancer Society. Among the topics to be discussed are : clinical use of steroids in gynæcology; growth and fattening of animals; metabolism and excretion of steroids; relation of structure to function of steroids ; lactation and reproduction in animals; clinical and experimental work on cancer; metabolism of convalescence; sex differentiation and steroids. The symposium will be open to the public. Further particulars can be obtained from Dr. Edgar S. Gordon, chairman Symposium Committee, University of Wisconsin.

The Science Co-operation Office in Cairo of the United Nations Educational, Scientific and Cultural Organisation has compiled a very useful list of scientific papers published in the Middle East and received by the Office up to March 1, 1948. The papers are classified under mathematics, mechanics and physics, chemistry, geology and geophysies, botany, zoology, medical sciences, engineering, agriculture and psychology, and there are single entries under palæontology and biology. Most of the entries are under zoology, medical sciences, agriculture and psychology. A list of periodicals re. viewed includes particulars of frequency, price and the name and address of the publisher, the periodicals being arranged by countries. 